Environment Conservation Journal 15(3) 149-155, 2014

ISSN 0972-3099 (Print) 2278-5124 (Online)

Abstracted and Indexed

\title{
Effect of 5-HTP and L-Dopa on lipid profile of Streptozotocin induced diabetic mice
}

\author{
UlkaYadav $\bowtie$ and Rajkumari Batham
}

Received:07.03.2014

Revised: 12.06.2014

Accepted:28.06.2014

\begin{abstract}
The present study was designed to test whether the precursor of serotonin (i.e.5-HTP) and dopamine (i.e. L-DOPA) can influence Body weight and certain hematological constitutes (i.e. blood glucose, glycosylated hemoglobin and serum protein) in streptozotocin induced diabetic mice. In the study, animals were divided into 6 groups. After 10 days at the termination of experiment body weight and blood glucose taken. Blood was collected from left ventricle and deposited to pathology for haematological analysis (i.e. blood Glucose, glycosylated heamoglobin, serum protein, triglyceride total cholesterol, HDL-cholesterol, LDC-cholesterol, and VLDL-cholesterol). Statistical analysis were done with the help of student's ' $t$ ' test followed by analysis of variance (ANOVA). The result of the present study suggest that peripheral administration of 5-HTP (a precursor of serotonin) and L-DOPA (a precursor of dopamine) influences the body weight gain and lipid profile (i.e. triglyceride, total cholesterol, HDL-cholesterol, LDL-Cholesterol, VLDC-cholesterol) in streptozotocin induce diabetic mice. The finding of the present study supports the concept that insulin alone does not fully control diabetes. Other chemical substance like neurotransmitter/hormones may involve in controlling the diabetes.
\end{abstract}

Keywords: Diabetes, L-Dopa, 5-HTP, Streptpzotocin, Female Albino mice

\section{Introduction}

Diabetes mellitus is a genetically determined disorder of the metabolism of carbohydrate, Protein and fats associated with a relative or absolute insufficiency of insulin secretion and with various degrees of insulin resistance, in which the level of blood glucose is persistently raised above the normal range. This disease is heterogeneous in nature. Differences between various forms of the disease are expressed in terms of etiology and pathogenesis (genetic, environmental and immune Factors), natural history and response to treatment. Diabetes therefore is not single disease but a syndrome.

Classification of DM: In most classification including that of National Diabetes Data Group (NDDG) Diabetes mellitus has been divided into two major categories:

1) Insulin dependent diabetes mellitus (IDDM) or juvenile onset diabetes or Type I diabetes.

2) Non-insulin dependent diabetes mellitus (NIDDM) or Maturity Onset diabetes or Type II diabetes.

Author's Address

Department of Zoology, Govt. MadhavScience College, Ujjain M.P., India

E-mail: ulka.yadav@gmail.com

Copyright by ASEA

All rights of reproduction in any form reserved (i) IDDM: This is known as juvenile onset diabetes mellitus because it usually occur inthe young though it may occur at any age and often shows second peak of incidence in 60-70 age group. There appears to be a seasonal variation in incidence in younger patients, highest in winter months and lowest in the summer. Cell mediated immunity may be present against pancreatic antigens and positive Pancreatic islet cell bodies (ICA) Occur in over 80 percent of patients at diagnosis. Certain human leucocytes antigens (HLA), also known as histocompatibility antigens, may determine the susceptibility to developing Type I Diabetes Mellitus.

(ii) NIDDM: This is known as maturity onset Diabetes Mellitus because it occurs usually after 40 years of age. Obesity is suspected as an etiological factor and on this basis type II Diabetes Mellitus has two subclasses-non obese and obese-noninsulin- dependent diabetics. There is no proven association with a viral etiology, autoimmunity or HLA type although identical twin studies show a strong genetic relationship. Some patients initially classified as type II DM may subsequently develop type 1 DM. These subjects often have a persistence 
of ICA and a family history of type I DM. In addition, type II diabetics may require insulin temporarily during stress. A comparison of the main differences in two types of diabetes mellitus is presented below.

\section{Chemical Agent capable of Inducing Diabetes:}

The use of chemical agent to produce diabetes permits detailed study of the biochemical, hormonal and morphologic events that occur during and after the induction of a diabetic state. The two agents that have been most extensively studied and have yielded the vast majority of information pertinent to human diabetes are alloxan and streptozotocin.

(i) Alloxan: Alloxan was first noted to have diabetogenic by Dunn in the course of studies on the effect of uric acid derivatives on kidney following trauma (Dunn et al., 1943). Its mechanism of action is not known

(ii) Streptozotocin (STZ): Streptozotocin, an Nnitroso derivative of $\mathrm{D}$-glucosamine was

initially isolated from cultures of streptomyces sachromogens, but subsequently has been synthesized in the laboratory (Herr et al., 1959). Like alloxan, streptozotocin is a relatively selective beta cytotoxin in certain animal species, causing an initial triphasic glucose response and then permanent diabetes.

Neurotransmitter: Over the last few decades several excellent reviews on this subject have been published, (Holmes and ball, 1974; Ball, 1981). Chemically neurotransmitters are biogenic amines. The important neurotransmitters are catecholamine's (dopamine, norepinephrine and epinephrine). Indolamines (serotonin or 5hydroxytryptamine), gamma amino butyric acid (GABA), acetylcholine and histamine. Out of this neurotransmitter, serotonin (5-HT) and dopamine (DA) appear to have central role in the regulation of not only hormonal rhythms but also of many events which usually occur at a specific time during a daily cycle. The sleep wakefulness cycle is characterized by alteration of serotonergic and catechiolaminergic activity. Serotonergic activity dominates during sleep, while catecholaminergic activity is stimulatory for waking process. Locomotors activity is stimulated by noradrenergic and dopaminergic activity and inhibited by serotonergic activity in fish mammals and birds (Fenwick, 1970; Mabry and Campbell, 1973; Pan, 1996).
Dopamine: Central nervous system, sympathetic post-ganglionic neurons and adrenal chromaffin tissue has identical process of biosynthesis of catecholamines including dopamine. The number of steps however depends on the end products secreted i.e., dopamine, nor limiting adrenaline and adrenaline (Axelord, 1974). First and rate limiting steps in catecholamines biosynthesis is the conversion of tyrosine into L-DOPA (L-dihydroxy phenilalanine) by the enzyme tyrosine hydroxylase. Aromatic L-Amino acid decarboxylase catalyses the conversion of L-DOPA to dopamine to norepinephrine, which is converted in to epinephrine by the enzyme phenyl ethanolamine $\mathrm{N}$ methyl transferase (PNMT).

Serotonin: Serotonin is an indolamine formed from the amino acid tryptophan. A Blood level of tryptophan appears to influence the rate of serotonin synthesis. The next step in the synthetic pathway is hydroxylation. If tryptophan by tryptophan hydroxylase at the 5 position to form 5hydroxytryptophan (5-HTP), which is almost immediately decarboxylated to serotonin after release is the catalytic action of enzyme monoamine oxydase (MOA). The major metabolite formed is 5-hydroxindolacetic acid (5HIAA).relatively little is known concerning the control of serotonin synthesis. Dopamine is a neurotransmitter that plays a critical role in neurological and psychiatric disorder, such as schizophrenia, Parkinson disease, and drug addiction (Callier et al., 2003). Increasing evidence also shows implication of dopamine in various physiological functions such as cell proliferation (Hoglinger et al., 2004). Gastrointestinal protection and inhibition of prolactin secretion (Freeman et $a l ., 2000)$ effects of dopamine on insulin secretion in general and on pancreatic. Beta cell functions in particular have been poorly studied. Insulin exocytosis from the beta cell is primarily controlled by metabolism- secretion coupling. First, glucose equilibrates across the plasma membrane and is phosphorylated by glucokinase, initiating glycolysis subsequently, mitochondrial metabolism generated ATP, which promotes the closure of ATP- sensitive potassium channels and as a consequence, depolarization of the plasma membrane. This leads to calcium influx through voltage-gated calcium channels and a rise in cytosolic calcium, triggering insulin exocytosis (Lang, 1999). Additional 
signals participating in the amplifying pathway (Henquin, 2000) are necessary to reproduce the sustained secretion elicited by further modulated by parasympathetic and sympathetic neurotransmitter (Ahren, 2000).

Streptozotocin-(STZ) included hyperglycemic state has been used as an animal model for diabetes mellitus (DM) (Bradberry et al;. 1989; McCall 1992). STZ selectively destroys pancreatic islet beta-cells and causes Hypoinsulinemia, leading to hyperglycemia (Arison et al. 1967; hoheneggar and rudas, 1971). STZ itself does not enter the brain, Studies of the chronic effect of STZ included DM on the concentration of dopamine (DA), its metabolites, and on DA receptors in rodent brain have shown: (1) reduced accumulation of 3,4dihydroxyphenylalanine (DOPA, a DA precursor) (Bradberry et al., 1989); (2) decreased concentration of DA metabolites 3,4dihydroxyphenylacetic acid (DOPA) and homovanillic acid (HVA) ( Bellus and Riel 1991; lackovic at al. 1990);(3) increased DA-D2 receptors (Lazovsk et al. 1981); and (4) decreased D receptors (Lackovic and Salkovic 1992) in rats STZ-or alloxan induced DM. The present study was designed to test whether to test precursor of serotonin (i.e. 5-HTP) and dopamine (i.e. L-DOPA) can influence body weight and lipid profiles in streptozotocin induced diabetic mice.

\section{Material and Methods}

\section{Care and Maintenance of Animals:}

Adult female albino mice weighing 15-25 were obtained from the veterinary collage whow and were maintained in the animal house of school of studies in Zoology and Biotechnology, Vikram University Ujjain, under controlled photoperiod regimen of $12 \mathrm{hrs}$ of lights (00.00 alternating to $20.00 \mathrm{hrs}$ ). Alternating with $12 \mathrm{hrs}$ of darkness (20.00to8.00hrs.) they were fed ad libitum everyday with standard chow diet and were given free access to water. Before the start of experiment, all the mice were given a period of 21 days for acclimatization. Animal described as fasting were deprived of good for at least 16 hours but were allowed free access to drinking water.

the dose of $50 \mathrm{mg} / \mathrm{kg}$ body weight 10days and served as STZ+5-HTP group.
Streptozotocin: Streptozotocin (Batch no. T1829656) was purchased From SISCO laboratories pvt. Ltd. Mumbai, and was freshly dissolved in $0.1 \mathrm{M}$ citrate buffer $(\mathrm{PH}=4.5)$ at the does of $50 \mathrm{mg} / \mathrm{kg}$ body weight and injected intraperitoneally within 15 minutes of dissolution in a vehicle volume of $0.4 \mathrm{ml}$ with $1 \mathrm{ml}$ of tuberculin syringe fitted with 24 gauges needle.

L-DOPA (L-Dihydroxyphenylalanine): MW197.19 Batch no.0.1106 Product no.037079, Central Drug House (P) Ltd. Bombay.

5-HTP (5-Hydroxytryptophan): MW-220.23, CAS 148290050 Product no. A0199225001 New Jersey USA 1-800 Across-01 Ceel, Belgium: +32 .

Induction of diabetes: Before the induction of diabetes, pretreatment fasting blood glucose concentrations of all the animals were determined with the help of glucometer using strips method and blood was taken out from the tip of the tail.

Diabetes in albino mice was induced with the help of an intraperitoneal injection of STZ at the dose of $50 \mathrm{mg} / \mathrm{kg}$ body weight. The appropriate dose were dissolved in $0.1 \mathrm{M}$ citrate buffer (PH4.5) and injected intraperitoneally within 15 minutes of dissolution in a vehicle volume of $0.4 \mathrm{ml}$, whereas a group of mice served as normal control was given citrate buffer only $(0.4 \mathrm{ml})$. Diabetes was confirmed by the determined fasting blood glucose concentration on the third day post administration of streptozotocin i.e. $48 \mathrm{hrs}$ after the STZ injection. Fasting blood glucose levels of all the method and blood was taken out from the tip of the tail. In the study animal were divided into 6 groups.

Group I consisted of 6 female mice were given injection of $.1 \mathrm{ml}$ normal saline once a day for 10 days. This group was served as normal control.

Group II consisted of 6 streptozotocin induced diabetic female mice. They received injection of 0.1 $\mathrm{ml}$ normal saline once a day for 10days. This group was served as diabetic control.

Group III consisted of 6 streptozotocin induced diabetic females mice. They received injection of L-DOPA at the dose of $50 \mathrm{mg} / \mathrm{kg}$ bodyweight in $0.1 \mathrm{ml}$ normal saline for 10days. This group was served as STZ+L-DOPA.

Group IV consisted of 6 STZ induced diabetic female mice. They received injection of 5-HTP at Group V consisted of 6 female mice and received injection of L-DOPA at the dose of $50 \mathrm{mg} / \mathrm{kg}$ body 
weight in $0.1 \mathrm{ml}$ normal saline for 10days and served as L-DOPA group.

Group VI consisted of 6 female mice and received injection of $5 \mathrm{HTP}$ at the dose of $50 \mathrm{mg} / \mathrm{kg}$ body weight in $0.1 \mathrm{ml}$ normal saline for 10days and served as 5-HTP group.

After 10days at the termination of experiment body weight and blood glucose were taken. Blood was collected from left ventricle and deposited to pathology for haematological analysis (i.e. triglyceride, total cholesterol, HDL- cholesterol, LDL- cholesterol, VLDL-cholesterol.

Statistical analysis was done with the help of student's ' $t$ ' test followed by analysis of variances (ANOVA) (Burning and Kintz, 1977).

\section{Results and Discussion}

Animal (Swiss albino mice, Musculusalbinus) treated with STZ (diabetic control) showed significantly $(\mathrm{P}<0.001)$ low body weight on 10days of post treatment. The other hand the animals group i.e. STZ+-DOPA, STZ+5-HTP,L-dopa and 5-
HTP treated showed significantly $(\mathrm{p}<0.50, \mathrm{p}<0.001)$ higher value of body weight on 10days of post treatment.(Fig-1). Lipid profiles (i.e. triglyceride, total cholesterol, HDL- cholesterol, LDLcholesterol and VLDL- cholesterol ) showed significantly $(\mathrm{p}<0.001)$ higher value in diabetic control (STZ treated mice ) while in other group i.e. STZ+L-DOPA, STZ +5-HTP, L-DOPA and 5-HTP lipid profiles were significantly $(\mathrm{P}<0.05, \mathrm{P}<0.001)$ low in comparison to diabetic control group (Fig-2 and 3). Streptozotocin is well known for its selective pancreatic islet cell toxicity and has used extensively in inducing diabetes mellitus in animals. STZ is taken up by beta cells via the glucose transporter GLUTZ and causes alkylation of DNA and reduction of ATP and NAD* content. STZ induces severe and irreversible hyperglycemia in experimental animals STZ was used to induce diabetes rather than alloxan since with STZ there is no incidence of spontaneous and more than $90 \%$ of rats become diabetic.

\section{Fig.1: Effect of 5-HTP and L-DOPA on Body weight in streptozotocin induced diabetic female mice. Value $=$ Mean \pm SE}

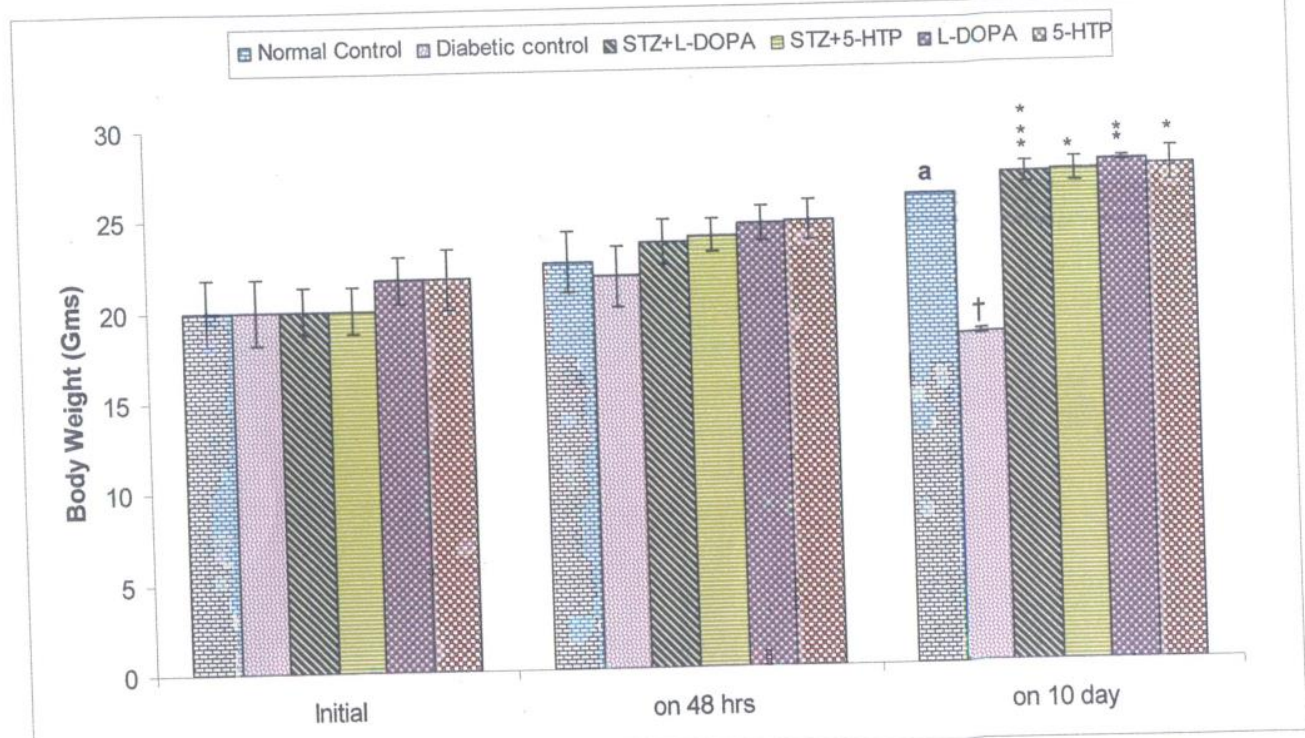

Significance of difference from control $\left(\dagger \mathrm{P}<0.001,{ }^{*} \mathrm{P}<0.05,{ }^{* *} \mathrm{P}<0.01,{ }^{* * *} \mathrm{P}<0.001\right.$; student's ' $\mathrm{t}$ ' test) ${ }^{\mathrm{a}}$ Experimental group differ significantly $(\mathrm{P}<0.001$; ANOVA) 
Fig.2: Effect of 5-HTP and L-DOPA on Triglyceride and Total Cholesterol in streptozotocin induced diabetic female mice. Value $=$ Mean $\pm S E$

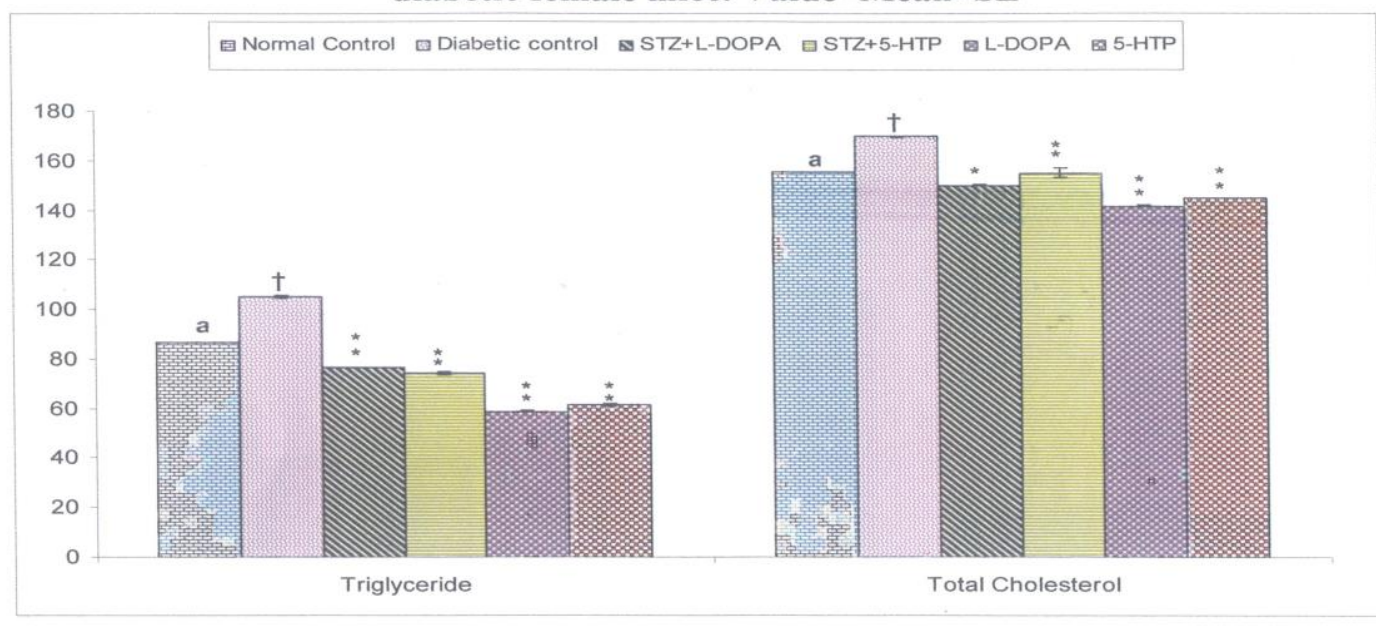

Significance of difference from control $\left(\dagger \mathrm{P}<0.001,{ }^{*} \mathrm{P}<0.05, * * P, 0.001\right.$; student's ' $t$ ' test)

${ }^{a}$ Experimental group differ significantly $(\mathrm{P}<0.001$; ANOVA)

Fig.3: Effect of 5-HTP and L-DOPA on HDL Cholesterol, LDL Cholesterol and VLDL Cholesterol in streptozotocin induced diabetic female mice. Value $=M e a n \pm S E$

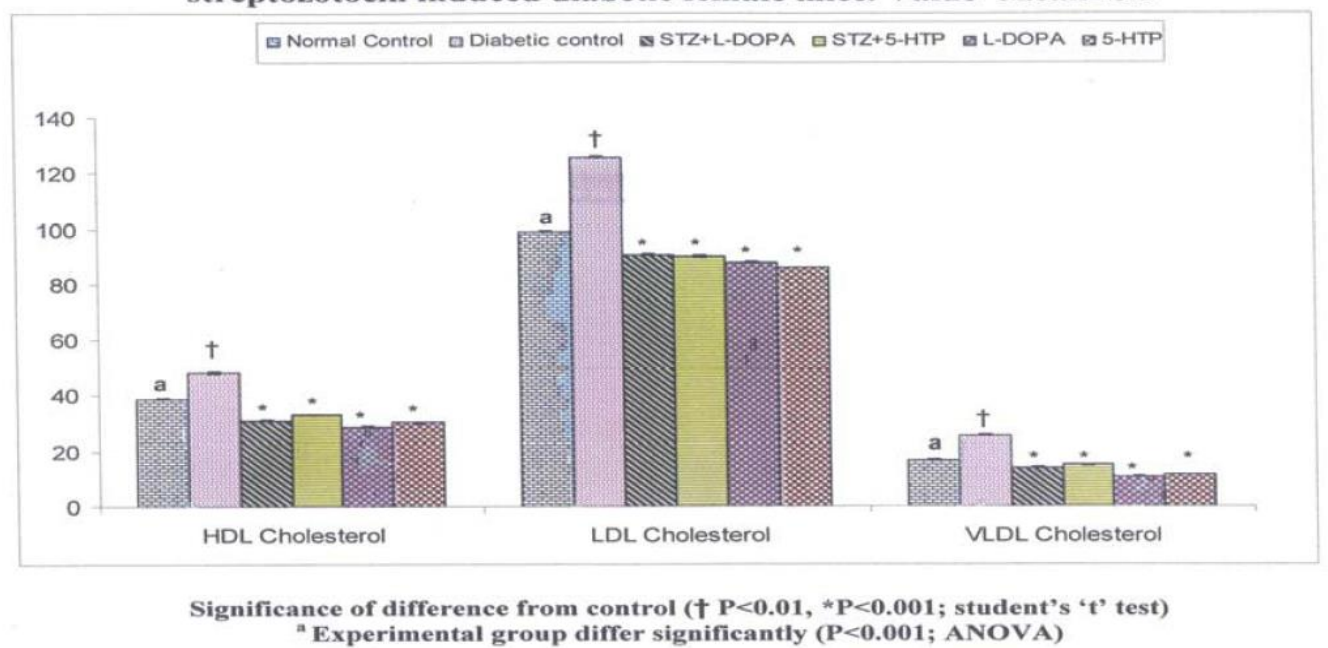

It is well documents from the animal studies that there is a significant decline in plasma insulin levels following STZ induced diabetes. For instance in male Wistar rat plasma insulin declined from $31.5 \mathrm{u} / \mathrm{ml}$ to $40 \mathrm{u} / \mathrm{ml}$ following $60 \mathrm{mg} / \mathrm{kg}$ body weight administration of STZ and from $188 \mathrm{pmol} / \mathrm{L}$ to $54 \mathrm{pml} / \mathrm{L}$ following $65 \mathrm{mg} / \mathrm{kg}$ body weight administration of STZ. In another study on CD-1 mice, five injection of STZ at a dose of $40 \mathrm{mg} / \mathrm{kg}$ body weight reduced the extractable insulin moderately but significantly. The islet cell specifically beta-cell mass is reduced in number in most diabetic patient.
The degree of reduction and the precise pathologic picture depends on the type of diabetes and duration. In the present study, the change in plasma glucose, HbA1c and plasma insulin levels can be correlated with histological alteration in pancreatic islets. Architectural disarray of islets, which is also extending to the exocrine (acinar tissue) part, the increase in intercellular space and peripheral widening (between acinar and islet cells) are some of the significant changes observed following STZtreatment. Observations in experiment animals have provided valuable information on the relationship between glycosylated hemoglobin and diabetes. Koening and ceramani (1975) have found that 
diabetic mice had increased levels of distinct minor hemoglobin component, which like human HbA1c had borohydride reducible linkages on the beta chain. Koeng et al; (1975) also found increased levels of HbA1c in several strains of mice with chemically induced diabetes. Wildness and his colleagues have found that glycosylated hemoglobin is increased in monkeys also when they become diabetic . Diabetes generally characterized by the deficiency of insulin which varies from an almost complete lack as seen in some with IDDM to a relative deficiency observed in many with NIDDM who have a major component of insulin resistance. Approximately, $80 \%$ of those with NIDDM are obese and have variable degrees of insulin resistance related to their obesity. The chemically induced models of diabetes are characterized by a partial or total deficiency of insulin. Usually clinical diabetes is different from experiment diabetes developed in animals show degenerative changes in beta cells and can be restored within few days.

The hormonal and metabolic derangement of diabetes mellitus is reflected not only in disordered carbohydrate metabolism, but also in abnormal mobilization and transport of fat. The majority of newly diagnosed and untreated diabetes have elevated plasma lipoproteins; there are the transport vehicles for lipids (i.e.cholestrol, cholesterol esters, triglycerides and phospholipids) in the blood stream. There are five complex lipoproteins that transport that the major serum lipids, chylomicrons, very low intermediate density lipoproteins (LDL), intermediate density lipoproteins (IDL) and high density lipoproteins (HDL).In view of the positive association between atherosclerosis and raised plasma levels of cholesterol end to lesser extent triglycerides, plasma lipid abnormalities have attracted considerable interest. Even though the correlation between plasma lipid abnormalities and risk of atherosclerosis in diabetes is not very well documented, the measurement of lipid profile still forms an important indice in diabetic subject. Besides carbohydrate and protein metabolism, insulin also affects lipid metabolism.It is reported that the derangement of glucose, fat and protein metabolism during result into the development of hyperlipidemia. Shilajit has been reported to produce beneficial effect in the lipid profile in alloxan- induced diabetic rats. In diabetic condition, an increase in blood glucose in accompanied with an increase in cholesterol level. In alloxan induced diabetic rats, the rise in blood glucose is accompanied by an increase in serum cholesterol and it was also found in our previous study and present study as well. Similar elevation in plasma cholesterol levels has also dose of $65 \mathrm{mg} / \mathrm{kg}$ body weight.The abnormal high concentration of serum cholesterol in diabetic animal is due, mainly to the increase in mobilization of the fatty acids from the peripheral fat depots, in the absence of insulin. On the other hand glucagons, catehalomines and other hormones enhance lipolysis. The marked hyperlipidemia that characterized the diabetic state may therefore be regarded as consequence of uninhibited action of lipolytic hormone on the fat depots. Polyherbal formulation at a dose of $20 \mathrm{mg} / \mathrm{kg}$ body weight for three weeks exhibited hypocholesteremic effect in STZ diabetic rats. A discovery that insulin alone does not fully control liver functions of glucose uptake, release and synthesis. A second hormone, serotonin, is released in the portal vein as a function of glucose presence in the gut and portal vein. In the take up and store glucose, and will, in fact, synthesis more glucose. Adult onset diabetes generally do not have a lack of natural insulin. Whenever a serotonin deficiency in the lacking control factor, this hormone is supplied by a hepatocyte diected vesicles (HDV) containing serotonin timed to reach the liver with the supply of glucose from a meal. STZ-treated animals showed clearly abnormal and urinary glucose concentrations and a several fold increase in urinary volume and sodium excretions. These increases in urinary volume and sodium excretions may result from the glomerular hyper filtrations that is associated with sever hyperglycemia. Glomerular hemodynamic alterations have been well documents in the rat with experimentally induced diabetes mellitus. The alterations in glomerular filtrations rate (GFR) in severely hyperglycemic rats mimic the changes in GFR observed in diabetic patients with degrees of hyperglycemia.

\section{References}

Ahren, B., and Lundquist, I 1985. Pharmacology 30, 71-82.

Ahren, B. 2000. Diabetologia 43, 393-410. 
Arison R.N., Ciaccio E.I., Glitzer M.S., C. Assaro A.B. 1967. Light and electron microscopy of lesions in rates rendered diabetic with streptozotocin. Diabetes 16:51-56.

Axelrod, J. 1974. The pineal gland: a neurochemical transducer. Science, 184: 1341-1348.

Ball, J.N. 1981. Hypothalamic control of the parsdistalis in fishes, amphibians and reptiles. Gen. Comp. Endocrinology., 44:135-170.

Belush LI, Reid SG 1991. Altered behavior and neurochemistry during short-term insulin withdrawal in streptozocin induced diabetic rats. Diabetes 40:217-222.

Bradberry C.W., Karasic, D.H., Deutch, A.Y., Roth, R.H. 1989. Regionally-specific alterations in mesotelencephalic dopamine synthesis in diabetic rats: Association with precursor tyrosine. J Neural Transm 78:221-229.

Callier, S., Snapyan, M., Crom, S., Prou, D., Vincent, J.D., and Vernier, P. 2003. Bio. Cell 95, 489-502.

Dunn, J.S., Sheehan, H.L. and McLethie, N.G.B. 1943. Necrosis of islets of Langerhans produced experimentally. Lancet, 1:484

Fenwick, J.C. 1970. Brain serotonin and swimming activity in goldfish, Carassiusauratus. Comp. Biochem., 32: 803-806.

Freeman, M.E., Kanyicska, B., Lerant, A., and Nagy, G. 2000. physiol. Rev. 80, 1523-1631

Henquin, J.C. 2000. Diabetes 49, 1751-1760.

Herr, R.R., Eble, T.E. Bergy, M.E. and Jahnke, H.K. 1959. Isolation and characterization of streptozotocin. Antibiot.Annu, 7:236.
Hery, M., Dusticier, G., Faudon, M., Barrit, M.C. and herr, F. 1980. Etude cimetique du metabolism de la 5-HT dans le nouyausuprachiasmatique de nat. Incidence Neuroendocrine. J. Physiol. (Paris), 77: 497-500.

Pan, J.T. 1996. Neuroendocrine functions of dopamine. In: CNS Neurotransmitter and Nuromodulators, Stone, T.W. Ed: Dopamine. Boca Raton, CRS Press, 213-232.

Hoglinger, G.U., Rizk, P., Muriel, M.P., Duyckaerts, C., Oertel, W.H., Caille, L., and Hirsch, E.C. (2004) Nat. Neurosci. 7, 726-735.

Hohenegger M, Rudas B 1971. Kidney functions in experimental diabetic ketosis. Diabetologia 17:334-338.

Holmes, R.L. and Ball, J.N. 1974. The pituitary gland: A Comparative Account, Cambridge University Press, and Cambridge, Mass.

Koeing, R.J. and Cerami, A. 1975. Synthesis of hemoglobin Alc in normal and diabetic mice: Potential model of basement membrane thickening. Proc. Natl. Acad. Sci., U.S.A., 72:3687-3691.

Lackovic Z, Salkovic M, Kuci Z, Relja M 1990. Effect of long lasting diabetes mellitus on rat and human brain monoamines. J Neurochemical. 54: 143-147.

Lang, J. 1999. Eur. J. Biochem. 259, 3-17.

Lozovsky D, Seller CF, Kopin IJ 1981. Dopamine receptor binding in increased in diabetic rats. Science 214: 10311033.

Mabry, P.D. and Campbell, B.A. 1973. Serotonergic inhibition of catecholamine induced behavioral arousal. Brain Res., 46: 381-391.

McCall Al 1992. Perspective in diabetes: The impact of diabetes on the CNS. Diabetes 41:557-570. 